\title{
How to change a shrimp into an intelligent drug carrier?
}

\author{
(INDEX: 16-22/2010 Copernican Letters ${ }^{\circledR}$ Vol 1) \\ Katarzyna Nawrotek, Roman Zarzycki and Zofia Modrzejewska \\ Faculty of Process and Environmental Engineering, Technical University of Lodz \\ Wólczańska 175 Street, 90-924 Lodz, Poland \\ Corresponding author: katarzynanawrotek@onet.eu
}

\begin{abstract}
Design of hybrid systems (structures composed of a carrier and pharmacological agent) for controlled release inside the body is a major direction in creation of new forms of drugs. These novel drug carriers should possess better accessibility and effectiveness with limited side-effects. The main purpose of this study was to construct a new form of chitosan carrier with the ability to transform from sol to gel at the physiological temperature of human body. Controlled drug release systems were formed by mixing $\beta$-sodium glycerophosphate with the solutions of chitosan glutaminate.
\end{abstract}

\section{Introduction}

Design of hybrid systems (structures composed of a carrier and pharmacological agent) for controlled release inside the body is a major direction in creation of new forms of drugs [1-5]. These novel drug carriers should possess better accessibility and effectiveness with limited side-effects.

Most often carriers contain cellulose and its derivatives in their structures [6-8]. But recently intensive studies have been carried out on the use of other natural polymers as drug carriers. Especially chitin and chitosan are examined [9-14].

\subsection{Chitin and chitosan}

Cellulose and chitin are polymers that are very abundant in the environment. Cellulose is a building material to protect organisms in the kingdom of plants and chitin in the kingdom of animals. Chitin can be found in crustaceans (such as crabs, shrimps, crayfish, krills and oysters), molluscs and insects [12, 15]. It forms also the cellular walls of some fungi and yeast
$[16,17]$. Chitin is produced in the amount of 10 gigatons $\left(1 \times 10^{13} \mathrm{~kg}\right)$ per year [18]. Commercially, the most easily accessible sources of chitin are the shells of marine crustaceans such as shrimps and crabs.

Cellulose and chitin have a similar structure (Fig. 1). They are made of linear $\beta-(1 \rightarrow 4)$-linked monosaccharide. However, their structures differ by the group at position C-2. At this site cellulose has the hydroxyl group and chitin has the acetamido group. The acetamido group in chitin makes that this compound is chemically inert, but it can be transformed into the amino group to give a very useful chemical compound - chitosan (Fig. 1).

\subsection{Conversion of chitin to chitosan}

Conversion of chitin into chitosan involves several chemical reactions $[10,15]$. In the first step chitin is purified from contaminations. Shells of marine crustaceans are composed of $15-40 \%$ of chitin, $20-40 \%$ of proteins, $20-50 \%$ of calcium carbonate, pigments and other metal salts (in very small amounts). To remove these contaminations, i.e. proteins, inorganic substances, pigments and lipids, the shells are treated with concentrated alcali solutions. Firstly, they are mixed with diluted hydrochloric acid at room temperature $\left(\mathrm{T}=20^{\circ} \mathrm{C}\right)$. In this reaction metal salts are removed. Secondly, the shells are treated with $1-2 \mathrm{~mol} / \mathrm{L}$ sodium hydroxide at 
the temperature about $\mathrm{T}=100{ }^{\circ} \mathrm{C}$. In these conditions proteins and pigments are decomposed. The alkaline treatment can be repeated a few times to make sure that these organic substances were removed.

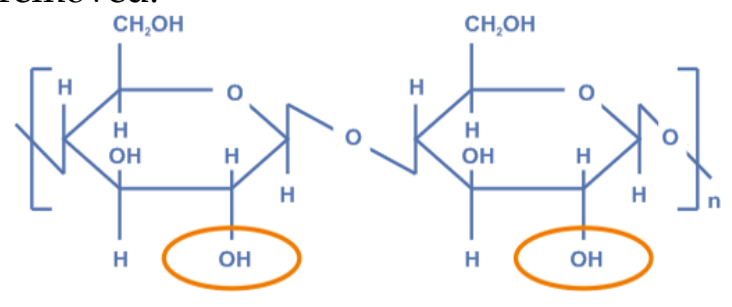

Cellulose

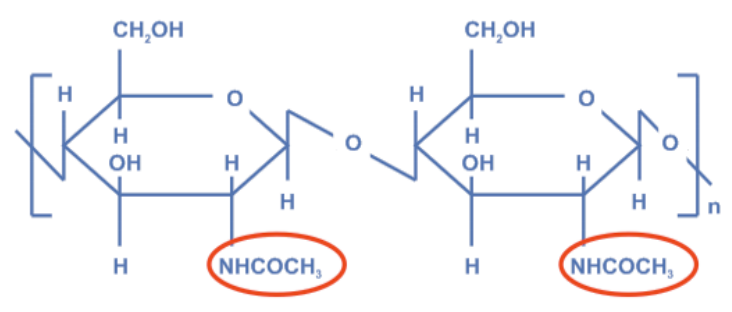

\section{Chitin}

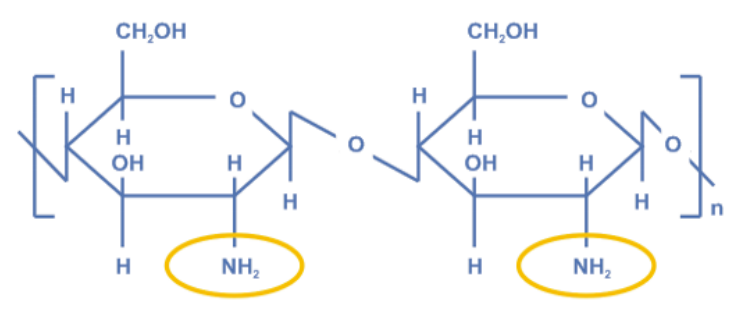

Chitosan

Fig.1. The structure of cellulose, chitin and chitosan. Their structures differ by the group at position $\mathrm{C} 2$.

In the next step chitin is transformed into chitosan. Chitosan is obtained in the reaction of chitin deacetylation with 40$50 \%$ aqueous alkali (mainly sodium hydroxide) at the temperature $\mathrm{T}=120 \div 150$ ${ }^{\circ} \mathrm{C}$.

Chitin and chitosan are long-chain polymers. The molecular mass of commercially available chitosan differs from 3800 to 20000 Daltons with the degree of deacetylation ranging between $66 \%$ and $95 \%$ [19].

\subsection{Unique properties of chitosan}

Chitosan is a cationic polysaccharide $[10,19]$. At neutral or basic $\mathrm{pH}$ it contains free amino groups which makes that it is insoluble in water. In acid environment it can be soluble in water as amino groups undergo protonation. In these conditions chitosan solubility is dependent on the distribution of $\mathrm{N}$-acetyl and free amino groups. Chitosan is usually dissolved in $1 \div 3 \%$ aqueous acetic acid solutions.

Chitosan has a unique combination of advantageous biological properties which are necessary in medical and pharmaceutical applications such as [10, 20]:

1. Biocompatibility with living tissues

- chitosan is not allergic and does not cause rejection;

2. Biodegradability - chitosan degrades to harmless and nontoxic products (amino sugars). Amino sugars are totally absorbed by the human body;

3. Nontoxicity;

4. Bacteriostatic - it has antimicrobial properties;

5. Wound-healing properties;

6. Immunostimulating activity;

7. Chitosan can absorb toxic metals such as lead, mercury and cadmium.

Moreover, chitosan and its derivatives have $[15,14]$ :

1. porous structure,

2. gel forming properties,

3. ease of chemical modification,

4. high affinity to in vivo macromolecules.

It is worth noting that production of chitosan is environmentally safe and inexpensive [21].

\subsection{Application of chitosan in drug delivery}

The aim of drug controlled release is predictable release of a drug into a specific release medium over an extended period of time. The structure of drug carriers should have the following properties: an optimal response to changes in the environment of the release medium, minimum side-effects to the 
human body and prolonged effectiveness [22-24].

There are two types of polymer drug carriers: reservoir device (an active agent is encapsulated) and matrix device (an active agent is absorbed). Drug release involves slow and controllable diffusion of an active agent from or through the polymer matrix. The drug can be released by erosion or degradation of the carrier as well (Fig. 2).

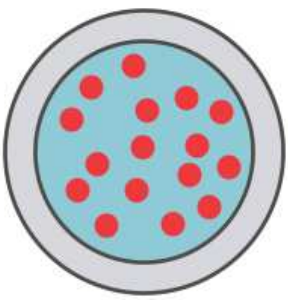

Reservoir device

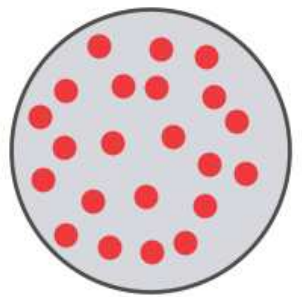

Matrix device
Fig.2. Schematic illustration of two types of diffusion-controlled spherical drug delivery devices [25].

Chitosan drug delivery systems can be prepared in the form of $[19,26]$ :

1. Tablets,

2. Capsules,

3. Microcapsules/microspheres,

4. Nanoparticles,

5. Beads,

6. Films,

7. Gels.

Hydrogels are a hydrophilic mixture which has the properties of both solid and liquid [27, 28]. The hydrogel structure consists of networks that are formed from randomly cross-linked macromolecules. Hydrogels have been widely examined for the use in controlled release applications [29-32].

Thermosensitive gels are produced from polymers having both hydrophilic and hydrophobic chemical groups. An increase of temperature causes weakness of polymer-water hydrogen bonds and, additionally, an increase of hydrophobic polymer-polymer interactions, e.g. dipol interactions, hydrogen bounds, van der Waals forces. A decrease of polymers from water solutions with an increase of temperature accompanies the rise of entropy. Finally, it leads to a change of chain structure to the form of floc, phase separation and in the case of threedimensional polymer matrix it is manifested by volume phase transition.

Chitosan carriers can also be in the form of tablets. This form has been widely described in the literature [26, 33-35].

A controlled-release chitosan matrix can be in the form of a microsphere. A microsphere is a particle in the shape of a sphere with the radius varying from $25 \mathrm{~nm}$ to $1 \mathrm{~mm}$. This sphere encapsulates a core substance. Due to their attractive properties microspheres are widely examined [36-49].

Table 1

Chitosan drug delivery systems for various kinds of drugs [19].

\begin{tabular}{|c|c|}
\hline Type of system & Drug \\
\hline Tablets & $\begin{array}{l}\text { diclofenac sodium, pentoxyphylline, } \\
\text { salicylic acid, theophylline, } \\
\text { propranolol } \mathrm{HCl}\end{array}$ \\
\hline Capsules & $\begin{array}{l}\text { insulin, } 5 \text {-amino salicylic acid } \\
\text { theophylline, cisplatin, pentazocine, }\end{array}$ \\
\hline $\begin{array}{l}\text { Microcapsules/ } \\
\text { microspheres }\end{array}$ & $\begin{array}{l}\text { diclofenac sodium, insulin, aspirin, } \\
\text { progesterone, propranolol } \mathrm{HCl} \text {, } \\
\text { vitamin D-2, bovine serum albumin, } \\
\text { ampicillin, ketoprofen }\end{array}$ \\
\hline Nanoparticles & $\begin{array}{l}\text { DNA, doxorubicin, insulin, bovine } \\
\text { serum albumin, ricin , cyclosporin A } \\
\text { adriamycin, nifedipine, bovine serum }\end{array}$ \\
\hline Beads & $\begin{array}{l}\text { albumin, salbutamol sulfate, } \\
\text { lidocaine- } \mathrm{HCl} \text {, riboflavin }\end{array}$ \\
\hline Films & $\begin{array}{l}\begin{array}{l}\text { Isosorbide dinitrate, chlorhexidine } \\
\text { gluconate, trypsin, riboflavine, }\end{array} \\
\text { testosterone, progesterone, beta- } \\
\text { oestradiol }\end{array}$ \\
\hline Gels & $\begin{array}{l}\text { chlorpheniramine maleate, aspiryn, } \\
\text { theophylline, caffeine, lidocaine-HCl, } \\
\text { hydrocortisone acetate, 5-fluorouracil }\end{array}$ \\
\hline
\end{tabular}

Chitosan drug delivery systems were used for various kinds of drugs (Table 1).

\section{Materials and Methods}

Thermosensitive chitosan gels were prepared by adding $\beta$-sodium glycerophosphate to the solutions of chitosan glutaminate at $2 \%$ polymer concentration. The system could be transformed from the solution into a gel 
at body temperature. It remained in the form of solution at physiological $\mathrm{pH}$ (7.0) and room temperature, but changed into a gel upon heating at physiological temperature $\left(37^{\circ} \mathrm{C}\right)$ and above.

Chitosan glutaminate hydrogels were prepared without albumin and with different amounts of albumin: $0.1 \mathrm{~g}$ (AL$0), 0.25 \mathrm{~g}$ (AL-025) and $0.5 \mathrm{~g}$ (AL-05).

Structures of the obtained gels are shown in the pictures below (Fig. 3 and Fig. 4).

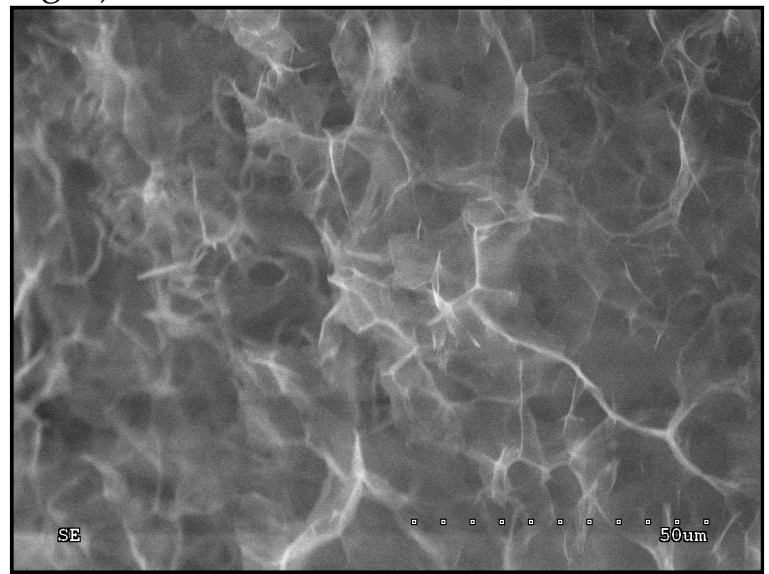

Fig.3. Scanning electron micrograph of hydrogel without albumin after lyophilization.

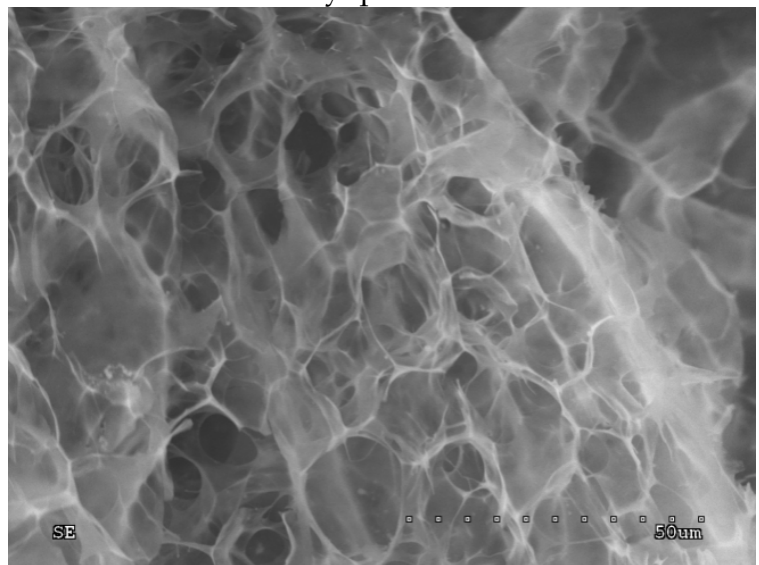

Fig.4. Scanning electron micrograph of hydrogel with albumin after lyophilization.

\section{Results and Discussion}

\subsection{In vitro release of a model drug}

The process was examined for hydrogels with different amounts of albumin $(0.1 \mathrm{~g}, 0.25 \mathrm{~g}$ and $0.5 \mathrm{~g})$. Drug release studies were performed in the ERWEKA apparatus (Fig. 5) for two frequencies of fluid mixing (50 rev/min and $100 \mathrm{rev} / \mathrm{min})$. The temperature of release medium was constant during the whole release process $\left(37^{\circ} \mathrm{C}\right)$.

The release was performed to distillation water of capacity $900 \mathrm{dm}^{3}$ and pH $5 \pm 0.5$.

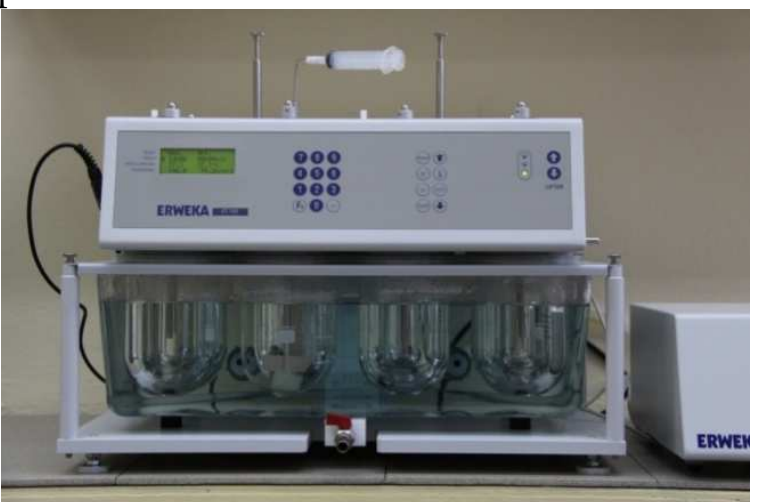

Fig.5. ERWEKA apparatus.

\subsection{Mathematical description}

The kinetics of albumin release was described by the Peppas equation, a so-called power law. This equation is used to describe the drug release profile from polymeric systems [40]. This empirical equation assumes a timedependent power-law function:

$$
\frac{C_{t}}{C_{\infty}}=k \cdot t^{n}
$$

where:

$\mathrm{C}_{\mathrm{t}}$ - the amount of molecule released up in any time $\mathrm{t},\left[\mathrm{g} / \mathrm{dm}^{3}\right]$,

$\mathrm{C}_{\infty}$ - the final amount of molecule release, $\left[\mathrm{g} / \mathrm{dm}^{3}\right]$,

$\mathrm{k}$ - the structural/geometric constant for a particular system, [-],

$\mathrm{n}$ - the release exponent representing a release mechanism, [-],

$\mathrm{t}$ - time, [h].

In this paper, the albumin release model is described for the range of time $\mathrm{t}=0 \div 5 \mathrm{~h}$. In this time the absorbance of the shadow is constant. It was assumed that the release of albumin depends on Fickian diffusion. Table 2 gives values of delivery matrices with different geometries and release mechanisms. For cylinder and Fickian diffusion the release exponent is equal $\mathrm{n}=0.45$. 
Table 2

Release exponent $n$ representing the drug release mechanism from polymeric controlled systems of different geometry [1]

\begin{tabular}{llll}
\hline Exponent, $\mathrm{n}$ & & & $\begin{array}{l}\text { Drug release } \\
\text { mechanism }\end{array}$ \\
\hline 0.5 & 0.45 & 0.43 & $\begin{array}{l}\text { Fickian } \\
\text { diffusion }\end{array}$ \\
$0.5<n<1.0$ & $0.45<n<0.89$ & $0.43<n<0.85$ & $\begin{array}{l}\text { Anomalous } \\
\text { transport }\end{array}$ \\
0.1 & 0.89 & 0.85 & $\begin{array}{l}\text { Polymer } \\
\text { swelling }\end{array}$ \\
\hline
\end{tabular}

For determination of a structural/geometric constant of the system $\mathrm{k}$ Peppas equation was described in the linear way.

$$
\log \left(\frac{C_{t}}{C_{\infty}}\right)=n \log t+\log k
$$

The schemes of the relationship $\log \left(\frac{C_{t}}{C_{\infty}}\right)=f(\log t)$ for samples AL-01, AL-025 and AL-05 were obtained in the program OriginPro 8 with determined slope equal to 0.45 (Fig. 6).

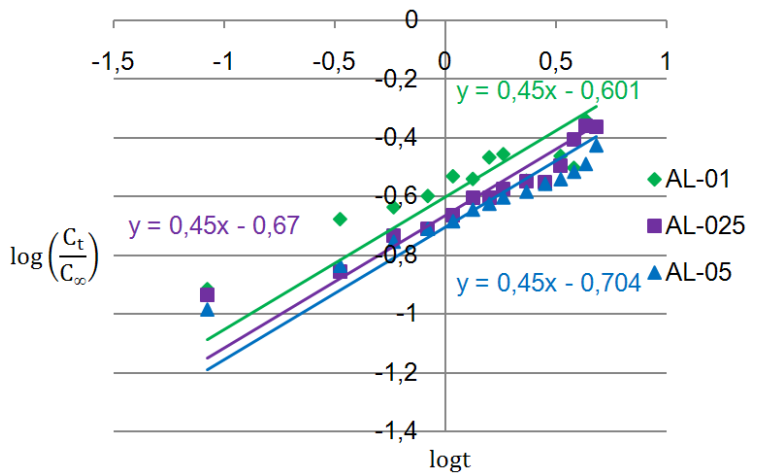

Fig.6. The relationship $\log \left(\frac{C_{t}}{C_{\infty}}\right)=f(\log t)$ for samples AL-01, AL-025 and AL-05.

The release profiles for samples AL01, AL-025 and AL-05 are described by the following equations:

For sample AL-01:

$$
\frac{C_{A L-01}}{C_{A L-01_{\infty}}}=0,25 \cdot t^{0,45}
$$

For sample AL-025:
$\frac{C_{A L-025}}{C_{A L-025_{\infty}}}=0,22 \cdot t^{0,45}$

For sample AL-05:

$\frac{C_{A L-05}}{C_{A L-05_{\infty}}}=0,20 \cdot t^{0,45}$

Figures 7 to 9 show the albumin profiles obtained from experimental data and the Peppas model.

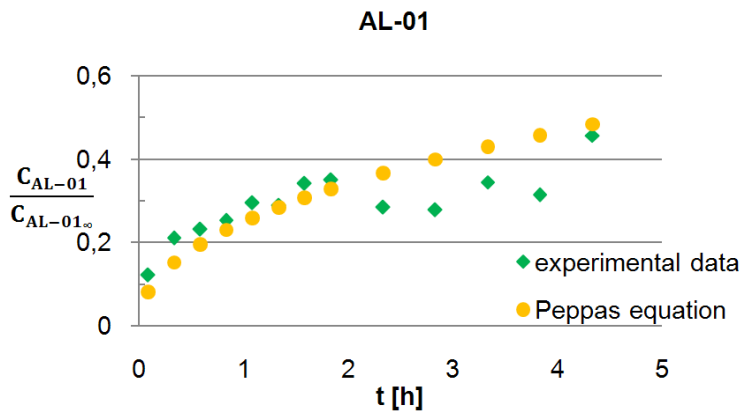

Fig.7. Comparison of model prediction vs. experimental data for AL-01.

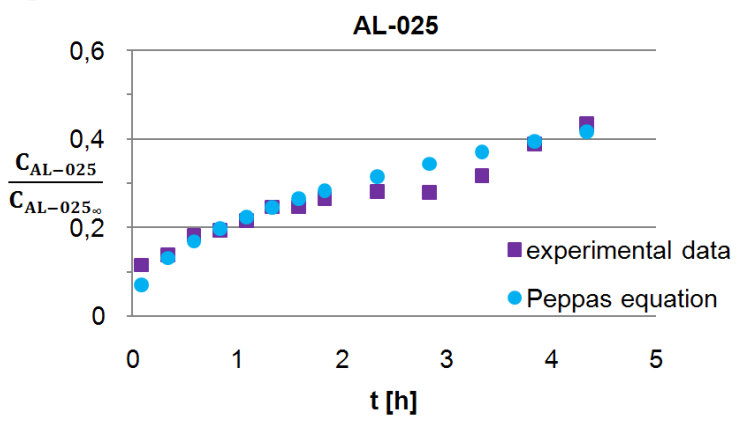

Fig.8. Comparison of model prediction vs. experimental data for AL-025.

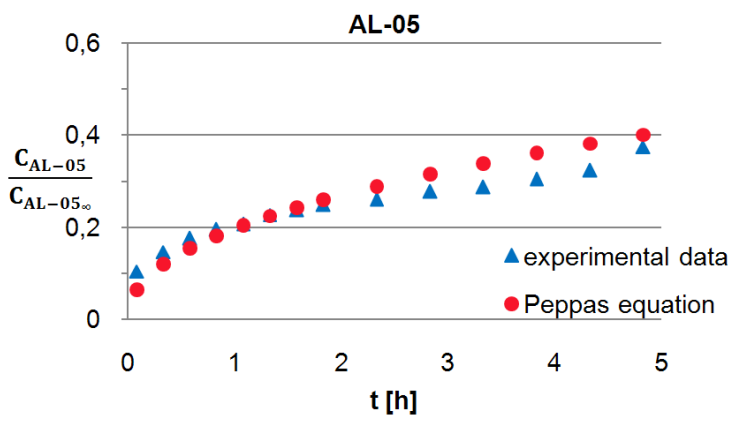

Fig.9. Comparison of model prediction vs. experimental data for AL-05. 
Drug release data fit well to the Peppas expression. The comparison of model prediction with experimental data indicates that the mechanism of drug release is controlled by diffusion.

\section{Conclusions}

Today there is tendency to use synthetic materials in almost every domain of our life. However their properties which are very important in the medicine and pharmacy, such as biodegradability and biocombability are worse and limited than those which posses natural polymers. For that reason natural polymers are very desired. Especially chitin and chitosan are very useful in medicine and pharmacy.

Drug delivery is one of the most prominent fields of research today, and the development of drug carriers is one of the main concerns. Chitosan and its derivatives are thus perfect materials for these applications. Chitosan carriers are quite flexible, soft and they are similar to natural tissues (in terms of biological and chemical properties). They can control the release of an active agent which is included in the carrier structure. Production of carriers is free of the use of hazardous organic solvents.

In the future, chitosan glutaminate hydrogels can be used as drug carriers in controlled drug delivery and as porous matrices, the so called scaffolds, in tissue engineering.

\section{References}

[1] Siepmann J., Siepmann F., Mathematical modeling of drug delivery, Int. J. Pharm., 2008, 364, 328-343.

[2] Lin C.C., Metters A.T., Hydrogels in controlled release formulations: Network design and mathematical modeling, Adv. Drug Deliv. Rev., 2006, 58, 1379-1408.

[3] Grassi M., Grassi G., Mathematical modelling and controlled drug delivery: Matrix systems, Curr. Drug Deliv., 2005, 2, 97-116.
[4] Cooke N. E., Chen C., A contribution to a mathematical theory for polymer-based controlled release devices, Int. J. Pharm., 1995, 115, 17-27.

[5] Siepmann J., Peppas N.A., Mathematical modeling of controlled drug delivery, Adv. Drug Deliv. Rev., 2001, 48, 137-138.

[6] Suzuki Y., Makino Y., Mucosal drug delivery using cellulose derivatives as a functional polymer, J. Contr. Release, 1999, 62, 101-107.

[7] Gren T., Bjerre C., Camber O., Ragnarsson G., In vitro drug release from porous cellulose matrices, Int. J. Pharm., 1996, 141, 53-62.

[8] Chang C., Duan B., Zhang L., Fabrication and characterization of novel macroporous cellulose-alginate hydrogels, Polymer, 2009, 50, 5467-5473.

[9] Alves N.M., Mano J.F., Chitosan derivatives obtained by chemical modifications for biomedical and environmental applications, Int. J. Biol. Macromol., 2008, 43, 401-414.

[10] Kurita K., Chitin and Chitosan: Functional Biopolymers from Marine Crustaceans, Marine Biotechnology, 2006, 8, 203-226.

[11] Muzzarelli R.A.A., Chitins and chitosans for the repair of wounded skin, nerve, cartilage and bone, Carbohydr. Polym., 2009, 76, 167-182.

[12] Rinaudo M., Chitin and chitosan: Properties and applications, Progr. Polymer Sci., 2006, 31, 603-632.

[13] Shepherd R., Reader S., Falshaw A., Chitosan functional properties, Glycoconj. J., 1997, 14, 535-542.

[14] Shi C., Zhu Y., Ran X., Wang M., Su Y., Cheng T., Therapeutic Potential of chitosan and its derivatives in regenerative medicine, J. Surg. Res., 2006, 133,185-192.

[15] Ravi Kumar M.N.V., A review of chitin and chitosan applications, React. Funct. Polym., 2000, 46, 1-27.

[16] Niederhofer A., Muller B.W., A method for direct preparation of chitosan with low molecular weight from fungi, Eur. J. Pharm. Biopharm, 2004, 57, 101-105.

[17] Jaworska M. M., Konieczna E., The influence of supplemental components in nutrient medium on chitosan formation by the fungus Absidia orchidis, Appl. Microbiol. Biotechnol., 2001, 56, 220-224.

[18] Harish Prashanth K. V., Tharanathan R. N., Chitin/chitosan: modifications and their unlimited application potential - an overview, Trends Food Sci. Tech., 2007, 18, 117-131.

[19] Agnihotri S. A., Mallikarjuna N. N., Aminabhavi T. M., Recent advances on chitosanbased micro- and nanoparticles in drug delivery, J. Contr. Release, 2004, 100, 5-28.

[20] Kim I. Y., Seo S. J, Moon H. S., Yoo M. K., Park I. Y., Kim B. C., Cho C. S., Chitosan and its 
derivatives for tissue engineering applications, Biotechnol. Adv., 2008, 26, 1-21.

[21] Schuetz Y.B., Gurny R., Jordan O., A novel thermoresponsive hydrogel based on chitosan, Eur. J. Pharm. Biopharm., 2008, 68, 19-25.

[22] Berger J., Reist M., Mayer J.M., Felt O., Peppas N.A., Gurny R., Structure and interactions in covalently and ionically crosslinked chitosan hydrogels for biomedical applications, Eur. J. Pharm. Biopharm., 2004, 57, 19-34.

[23] Jeong B., Gutowska A., Lessons from nature: stimuliresponsive polymers and their biomedical applications, Trends Biotechnol., 2002, 20, 305-311.

[24] Klouda L., Mikos A.G., Thermoresponsive hydrogels in biomedical applications, Eur. J. Pharm. Biopharm., 2008, 68, 34-45.

[25] Zarzycki R., Modrzejewska Z., Nawrotek K., Drug release from hydrogel matrices, Ecol. Chem. Enginer. S, 2010, 17, 117-136.

[26] Illum L., Chitosan and its use as a pharmaceutical excipient, Pharm. Res., 1998, 15, 1326-1331.

[27] Li H., Luo R., Lam K. Y., Modeling of environmentally sensitive hydrogels for drug delivery: An overview and recent developments, Front. Drug Des. Discov., 2006, 2, 295-331.

[28] Van Tomme S.R., Storm G., Hennink W.E., In situ gelling hydrogels for pharmaceutical and biomedical applications, Int. J. Pharm., 2008, 355, 118.

[29] Barbucci R., Hydrogels: Biological properties and applications, Milan : Springer, 2009.

[30] Bajpai A. K., Shukla S. K., Bhanu S., Kankane S., Responsive polymers in controlled drug delivery, Progr. Polym. Sci., 2008, 33, 10881118.

[31] Drury J. L., Mooney D. J., Hydrogels for tissue engineering: scaffold design variables and applications, Biomaterials, 24 (2003), 4337-4351.

[32] Qiu Y., Park K., Environment-sensitive hydrogels for drug delivery, Adv. Drug Deliv. Rev., 2001, 53, 321-339.

[33] Ofori-Kwakye K., Fell J. T., Biphasic drug release from film-coated tablets, Int. J. Pharm., 2003, 250, 431-440.

[34] Miyazaki S., Nakayama A., Oda M., Takada M., Attwood D., Drug release from oral mucosal adhesive tablets of chitosan and sodium alginate, Int. J. Pharm., 1995, 118, 257-263.

[35] Koizumi T., Ritthidej G. C., Phaechamud T., Mechanistic modeling of drug release from chitosan coated tablets, J. Contr. Release, 2001, 70, 277-284.

[36] He P., Stanley S., Davis S. S., Illum L., In vitro evaluation of the mucoadhesive properties of chitosan microspheres, Int. J. Pharm., 1998, 166, 75-68.
[37] He P., Stanley S. Davis S. S., Illum L., Chitosan microspheres prepared by spray drying, Int. J. Pharm., 1999, 187, 53-65.

[38] Giunchedi P., Genta I., Conti B., Muzzarelli R. A. A., Conte U., Preparation and characterization of ampicillin loaded methylpyrrolidinone chitosan and chitosan microspheres, Biomaterials, 1998, 19, 157-161.

[39] Jameela S. R., Kumary T. V., Lal A. V., Jayakrishnan A., Progesterone-loaded chitosan microspheres: a long acting biodegradable controlled delivery system, J. Contr. Release, 1998, $52,17-24$.

[40] Peppas N. A., Bures P., Leobandung W., Ichikawa H., Hydrogels in pharmaceutical formulations, Eur. J. Pharm. Biopharm., 2000, 50, 2746 